\title{
Characterisation of fibroblast-like cells in pannus lesions of patients with rheumatoid arthritis sharing properties of fibroblasts and chondrocytes
}

Chengsen Xue, Masayoshi Takahashi, Tomoko Hasunuma, Hiroyuki Aono, Kazuhiko Yamamoto, Shinichi Yoshino, Takayuki Sumida, Kusuki Nishioka

\begin{abstract}
Objective-To better understand the characteristics of synoviocytes located in the rheumatoid arthritis (RA) pannus.

Methods-One cell line, termed PSC, was cloned from RA pannus lesions. Phenotypic analysis was done by contrast microscopy, indirect immunostaining, and safranin $O$ staining. Transcription of several protooncogenes and matrix degrading enzymes was evaluated. The expression of mRNA for collagen II was detected by in situ hybridisation. The ability of anchorage independent growth was assessed by soft agarose culture.

Results-PSCs showed a high transcription of protooncogenes c-fos, c-myc and c-jun. They also expressed mRNA for matrix degrading enzymes, such as collagenase, cathepsin $B$, and cathepsin $L$. Anchorage independent growth assay demonstrated that PSCs formed colonies in soft agar culture. Phenotypic analysis showed that this fibroblast-like PSC was stained intensely with anti-vimentin and anti-fibroblast antibody. In situ reverse transcriptase assay showed that the cell line expressed type II collagen mRNA. Conclusion-Alternative fibroblast-like cells were identified in the pannus lesion of RA sharing properties of fibroblasts and chondrocytes. These findings suggest that this fibroblast-like cell derived from pannus lesions may contribute to the destruction of the cartilage in RA.
\end{abstract}

(Ann Rheum Dis 1997;56:262-267)

Pannus formation is a prominent feature of rheumatoid arthritis (RA). Several reports have suggested that pannus expresses 'aggressive, invasive and tumour-like' properties. ${ }^{1-4}$ Moreover, pannus synoviocytes have been suggested to represent a $\mathrm{T}$ cell independent pathway responsible for joint destruction in RA. ${ }^{5}$ Such synoviocytes express excessive amounts of vascular cell adhesion molecules, but a large part of phenotypic and functional features of pannus synoviocytes remains obscure.

Although the origin of pannus is still under debate, ${ }^{6-9}$ observations based on detailed morphological studies have provided sufficient evidence indicating that the area of cartilagepannus junction contains chondrocyte derived cells, ${ }^{10}$ that react with monoclonal anti-type II collagen antibodies. ${ }^{11}$ The articular cartilage has been considered to contribute, at least in part, to the formation of pannus. ${ }^{910}$ Others have suggested that the immature mesenchymoid cells serve as a source for initiating pannus formation. ${ }^{12}$ Because of the limitation of conventional histochemical stains, isolation techniques, and culture conditions used, a putative distinct cell population, which may be different from the well characterised synovial lining cells, has not been isolated and well characterised..$^{13}$ In this study, we isolated a cell line, termed PSC, from biopsy specimens of RA pannus. The phenotypic and functional features of the cell line were characterised.

\section{Methods}

CELL PREPARATION

Synovial tissue samples were obtained during arthroplasty from the knee joints of two female patients (aged 69 and 72 years) with clinical and laboratory features consistent with RA according to the criteria of American College of Rheumatology. During the operation, pannus samples were carefully selected from granulation tissue invading the articular cartilage of the femur and tibia. At the same time, synovial tissue samples from the hypertrophic villi surrounding the joint capsule were obtained, which served as non-pannus samples (SC). As a control, synovial tissues from two female patients with osteoarthritis (OA) and one female patient with traumatic joint injury were also obtained during knee surgery. The control sample was taken from tissues far from the cartilage area. The experimental protocol was approved by the Ethics Review Committee for Human Experimentation at our institution and a signed consent form was obtained from all subjects.

Cloning of synovial cells was performed according to the method described previously by our laboratory. ${ }^{14}$ Briefly, following removal of adipose tissue from the biopsy material, the specimen was minced into small pieces and digested with $1.0 \mathrm{mg} / \mathrm{ml}$ of collagenase (Sigma Chemical Co, St Louis, MO) in Dulbecco's modified Eagle's medium (DMEM, GIBCO Laboratories, Grand Island, NY) at $37^{\circ} \mathrm{C}$ for two hours. After digestion, the dissociated cells were collected by centrifugation at $500 \mathrm{~g}$ for five minutes, resuspended in Ham F-12 medium (GIBCO Laboratories) supplemented with $10 \%$ fetal calf serum (FCS, Bioserum, Melbourne, VIC, Australia), $100 \mathrm{U} / \mathrm{ml}$ penicillin, $100 \mathrm{mg} / \mathrm{ml}$ streptomycin, and $5 \times 10^{-5} \mathrm{M}$ 2-mercaptoethanol (2-ME). The cell suspen-
Accepted for publication 27 November 1996 
sion was then poured into a $90 \mathrm{~mm}$ diameter dish (Sumitomo Medical Co, Tokyo). The adherent synoviocytes became confluent in three to five days and served as the primary culture. A limited dilution method was established for developing colonies. Briefly, the cells in culture were detached using $0.25 \%$ trypsin (GIBCO Laboratories), collected by centrifugation at $500 \mathrm{~g}$ for three minutes, and resuspended in Ham F-12. After counting, the cells were seeded into 96 well flat bottom plates (Corning Glass Works, Corning, NY) at a density of 0.5 cells per well. Single cells were picked up and expanded. In addition, cells forming colonies in soft agar culture (see below) were also picked up and expanded in 90 $\mathrm{mm}$ dishes. These cells were termed PSC.

INDIRECT IMMUNOFLUORESCENCE

Phenotypic analysis was performed by indirect immunofluorescence test using fluorescein isothiocyanate (FITC) conjugated monoclonal antibodies (MAbs). All MAbs used in the study were purchased from commercial sources, and included anti-vimentin and 5B5 (DAKO A/S, Glostrup, Denmark), MY4, a monocyte/macrophage marker (CD14, Coulter Immunology, Hialeah, FL), and several antibodies including S100, LCA, DRC-1 and CD35 (DAKO A/S), S100A (DAKO Co, CA) and Leu6 (Becton-Dickinson, Mountain View, CA). Mouse IgG1 (Coulter Immunology) was used as a control. Briefly, cells were seeded into slide chambers (Nunc Inc, Naperville, IL) at a density of $3 \times 103$ cells per chamber. After a culture period of five days, the slides were fixed with cold acetone and subjected to indirect immunostaining as described previously. ${ }^{15}$ The results were evaluated using a fluorescence microscope.

STAINING WITH SAFRANIN O

Staining with safranin $\mathrm{O}$ was performed according to the method described by Ishikawa et $a l .{ }^{16}$ The cells studied were grown in slide chambers. The chambers were incubated at $37^{\circ} \mathrm{C}$ and $5 \% \mathrm{CO}_{2}$ in air. The slides were fixed five days later with acetone, and then immersed into $0.2 \%$ solution of safranin $\mathrm{O}$ (Schmid $\mathrm{GmbH}$, Kongen, Germany). The staining procedure lasted for two hours.

Table 1 Oligonucleotide sequences used in PCR amplification

\begin{tabular}{|c|c|c|c|c|}
\hline Gene & Primer & Position & Sequence & $\begin{array}{l}\text { GenBank } \\
\text { Accession No }\end{array}$ \\
\hline \multirow[t]{2}{*}{ c-fos } & Fos5L & $2490-2511$ & AGGAGAATCCGAAGGGAAAGGA & \\
\hline & Fos6R & $3000-2979$ & AGTCATCAAAGGGCTCGGTCTT & K00650 \\
\hline \multirow[t]{2}{*}{$\mathrm{c}-\mathrm{myc}$} & Myc1L & 1374-1395 & TCCTGGCAAAAGGTCAGAGTCT & \\
\hline & Myc2R & $1624-1602$ & TCTTGACATTCTCCTCGGTGTC & V00568 \\
\hline \multirow[t]{2}{*}{ c-jun } & c-jun $1 \mathrm{~L}$ & $1275-1296$ & GGAAACGACCTTCTATGACGAT & \\
\hline & $c-j u n 2 R$ & $1590-1571$ & GAACCCCTCCTGCTCATCTG & J04111 \\
\hline \multirow[t]{2}{*}{ Cathepsin L } & CAT1L & $232-253$ & AGTTTAGAGGCACAGTGGACCA & \\
\hline & CATL2R & $444-423$ & GCCATTCATCACCTGCCTGAAT & M20496 \\
\hline \multirow[t]{2}{*}{ Cathepsin B } & CTB1L & $974-995$ & GCTCTACAAGTCAGGAGTGTAC & \\
\hline & CTB2R & $1182-1161$ & GAATTCCAGCCACCACTTCTGA & M14221 \\
\hline \multirow[t]{2}{*}{ Collagenase } & Coll1L & $55-75$ & ATGCACAGCTTTCСТCCACTG & \\
\hline & Coll2R & $220-240$ & TTCAACCACTGGGCCACTATT & M15996 \\
\hline \multirow[t]{2}{*}{$\beta$ actin } & BAC1L & 1561-1581 & AAGGCCAACCGCGAGAAGATG & \\
\hline & BAC4R & $2596-2575$ & AAGGTAGTTTCGTGGATGCAAC & M10277 \\
\hline
\end{tabular}

All primers are shown in 5' to 3' direction. Sense strand oligonucleotides are indicated with an L and antisense oligonucleotides with an $\mathrm{R}$.
IN SITU REVERSE TRANSCRIPTASE ASSAY In situ reverse transcription was performed using the Digoxigenin Detection System Kit (Kreatech Biotechnology BV, Amsterdam). ${ }^{17}$ Briefly, cells were seeded into slide chambers. After culture for three days, they were fixed with $10 \%$ paraformaldehyde for one hour. The cells were treated with $0.5 \%$ NP-40 for one hour to ensure permeability. Ten $\mu \mathrm{l}$ of hybridisation mixture containing 5.0 pM type II collagen primer (5'GAGGCAGTCTTTCACGTCTTCA-3'), 10 $\mathrm{mM}$ DTT, $1.0 \mathrm{mM}$ dNTP, $10 \mathrm{U} / \mathrm{ml}$ reverse transcriptase, $2 \mathrm{U} / \mathrm{ml}$ RNase inhibitor, and 0.1 $\mathrm{nM}$ digoxigenin-11-dUTP was added. Each slide was covered with a coverslide and incubated at $42^{\circ} \mathrm{C}$ for one hour. The coverslides were removed at a later stage by washing with $2 \times$ standard saline citrate buffer (SSC, $150 \mathrm{mM} \mathrm{NaCl}, 15 \mathrm{mM}$ sodium citrate, $\mathrm{pH}$ 7.0). They were incubated with $100 \mu \mathrm{l}$ of rhodamine-conjugated sheep anti-digoxigeninFab fragments at room temperature for one hour, and then rinsed in phosphate buffered saline. The results were evaluated under a confocal microscope. Reaction with type II collagen sense primer was used to monitor non-specific binding.

RNA PREPARATION AND SEMI-QUANTITATIVE REVERSE TRANSCRIPTION PCR (RT-PCR)

After $5 \times 10^{5}$ cells were cultured in near confluent status, RNA was extracted from the cells using the AGPC method ${ }^{18}$ and analysed semiquantitatively by RT-PCR with Mo-MuLV reverse transcriptase (GIBCO Laboratories). ${ }^{19}$ Table 1 summarises the primers used in the present experiment for determining the individual expression. The sequence numbers correspond with those of the GenBank database. Amplification of $\beta$ actin mRNA served as a loading control. PCR was performed on a thermocycler (Hybaid Limited, Middlesex, UK) in a $50 \mu$ reaction volume, including cDNA sample, $2.0 \mathrm{U}$ Taq DNA polymerase (GIBCO Laboratories), 50 pmol of each primer, $200 \mathrm{mmol}$ of each deoxynucleotide triphosphate and $5 \mathrm{mCi}(\alpha-32 \mathrm{P})$ dCTP (NEN, Wilmington, DE). The annealing temperature was $64^{\circ} \mathrm{C}$ for one minute. PCR products were separated by $10 \%$ polyacrylamide gel electrophoresis. The gel was exposed to an $x$ ray film, and the bands on the film were measured under a densitometer with an image analyser (TIAS Image PRO, ACI Japan Co, Kanagawa). The ratio of the individual density of the protooncogene $/ \beta$ actin was calculated.

ANCHORAGE INDEPENDENT GROWTH ASSAY An anchorage independent growth assay similar to that described by Lafyatis et $a l^{20}$ was performed in six well plates (Corning Inc) with minor modifications. A gel mixture of $0.55 \%$ SeaPlaque agarose (FMC BioProducts, Rockland, ME) was prepared and used to precoat each well. Eighty per cent of confluent synoviocytes were washed twice in phosphate buffered saline, trypsinised, centrifuged, and resuspended in Ham F-12 medium supple- 
mented with $10 \%$ fetal calf serum. In the next step, $2.0 \mathrm{ml}$ of the soft agar solution $(0.33 \%$ agarose in Ham), consisting of 10000 synoviocytes, was spread over the base layer. The plates were incubated at $37^{\circ} \mathrm{C}-5 \% \mathrm{CO}_{2}$. All wells were examined daily for colony growth. Colonies formed in 10-14 days after seeding. Three weeks later, the number of colonies was counted under a contrast microscope. The cells in colonies were picked up and expanded in $90 \mathrm{~mm}$ dishes.

\section{Results}

MORPHOLOGICAL CHARACTERISTICS OF PSCS Morphological studies were performed to determine the characteristics of PSC. According to our previous classification, ${ }^{14} \mathrm{RA}$ synoviocytes are heteromorphous, consisting of three types, including dendritic cells, macrophage cells, and fibroblast-like cells. PSCs were homogeneous (fig 1A) and phenotypically resembled fibroblasts. However, they expressed more filopodia and spherical phase-dense cytoplasmic granules (fig 1B) than that of SCs. The cytoplasm of PSCs was oval or rhombic in shape. When the cells became confluent on culture dishes, they resembled fibroblasts. In addition, morphologically, there are no hyaline cartilage cells in the culturing PSCs under contrast microscopy.

IMMUNOFLUORESCENCE STAINING

To further characterise the phenotype of PSC, the cells were stained with several MAbs. PSCs were intensely stained with MAb to vimentin. The intermediate filament vimentin exists on fibroblast cells and epithelial cells as well as the mononuclear phagocyte system. ${ }^{21}$ Vimentin surrounded the nucleus and extended out to the cell periphery (fig 2). The synoviocytes were also immunostained positively with 5B5 antibody, but reacted weakly with antibody MY4 of the monocytes/macrophage surface marker. The cells failed to stain with antibodies such as S100, S100A, LCA, DRC-1, and CD35.

STAINING WITH SAFRANIN O

Safranin O is known to react with proteoglycan present in the cartilage and has been used as a marker for chondrocyte-like cells. Safranin O was positive in PSCs (fig 3) but not in SCs.
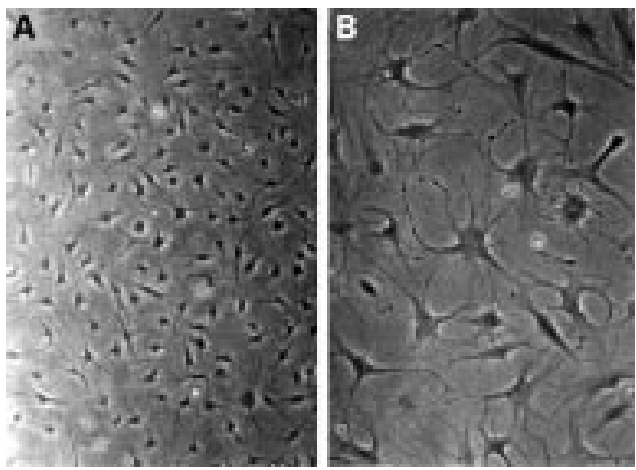

Figure 1 Contrast microscopy of cultured pannus synoviocytes. PSCs were cultured in a $90 \mathrm{~mm}$ dish. They were a homogeneous group of cells $(A)$ and had many filopodia (B) (original magnification $\times 200$ ).

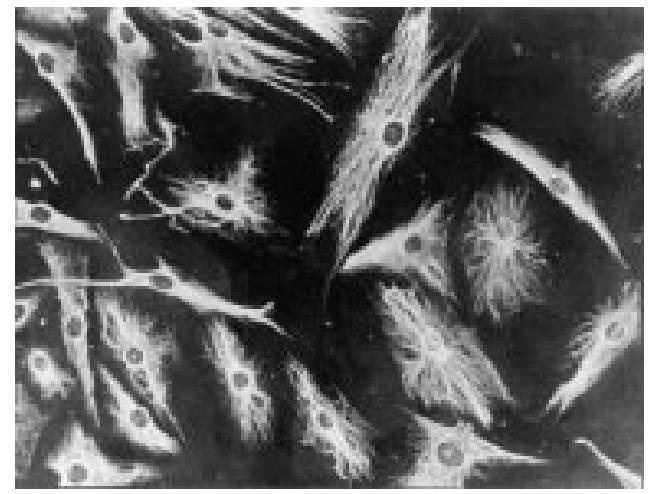

Figure 2 Immunofluorescence micrograph of vimentin filaments in cultured PSCs. Under contrast microscope, almost all PSCs were stained with anti-vimentin antibody labelled with FITC. The network of intermediate filament vimentin was stained with antibody to vimentin protein. An extensive network of vimentin filament surrounds the nucleus and extends out to the cell periphery (fluorescence microscopy, original magnification $\times 400$ ).

More than half of cloned PSCs picked up from soft agarose showed positive results. The percentage of positive cells in those with several filopodia was higher compared with spindle cells. Both the cytoplasm and nuclei of PSCs were stained, but the latter showed a less dense staining. In addition, as the passage of cells was increased, the positive staining gradually decreased. Almost all cells were negative after the eighth passage.

IN SITU REVERSE TRANSCRIPTASE ASSAY FOR TYPE II COLLAGEN MRNA

To confirm the chondrocyte nature of PSC, we evaluated the expression of mRNA for type II collagen by in situ reverse transcriptase assay. Confocal microscopy demonstrated detectable expression of type II collagen mRNA transcripts in PSCs from both rheumatoid

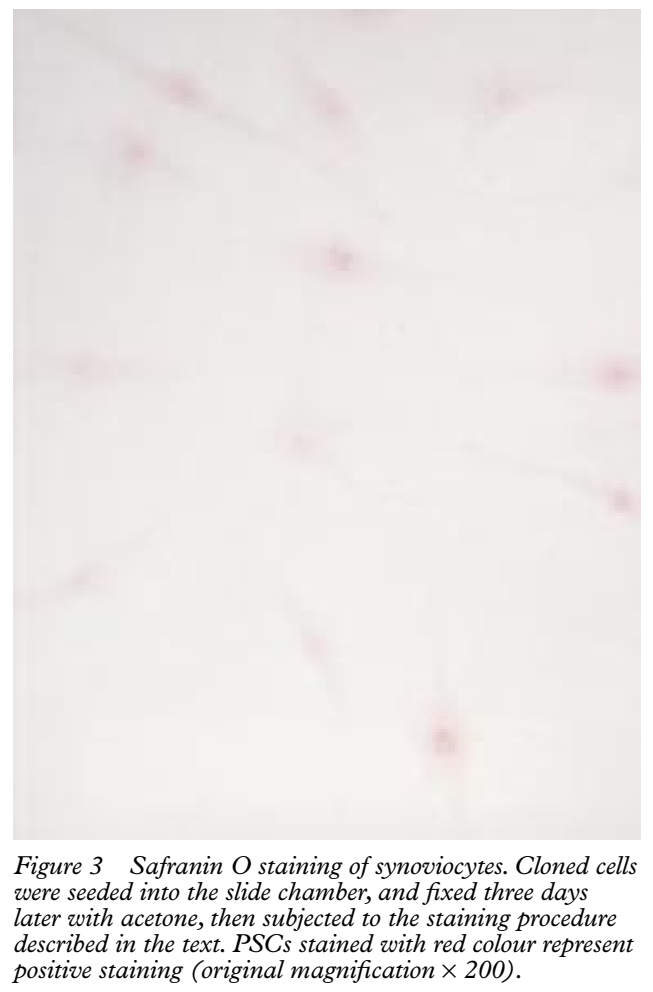


patients. In contrast, SCs from the same patient, and patients with $\mathrm{OA}$ and traumatic joint injury were negative for the gene. Quantitative evaluation by in situ reverse transcriptase assay demonstrated that less than $5 \%$ of the cells in primary bulk culture of pannus specimens showed mRNA expression of type II collagen, suggesting that these cells might represent the PSC phenotype. All cells that were picked up from the soft agar were positive (fig 4A). These cells also expressed several filopodia (fig 4B). Characteristically, type II collagen mRNA in cultured PSCs showed a scattered pattern, and were distributed over or adjacent to the nuclei.

EXPRESSION OF PROTOONCOGENES AND PROTEASE Semi-quantitative RT-PCR assay was used to examine the relative expression level of different protooncogenes, including c-myc, c-fos and c-jun in synoviocytes. To accurately control PCR amplification of all genes for the plateau phenomenon, the PCR conditions were modified in a cycle dependent manner. The most suitable cycle numbers were 16 cycles for $\beta$ actin, 28 cycles for c-myc, and 30 cycles for c-fos and c-jun. These protooncogenes were expressed in synoviocytes obtained from RA pannus as well as non-pannus synoviocytes. However, PSCs expressed larger amount of protooncogenes compared with SCs (table 2).

Synoviocytes derived from RA are well known to secrete several matrix degrading enzymes, such as collagenase, cathepsin B, and cathepsin L. The expression of such genes in PSCs was examined by RT-PCR. Both PSCs and SCs were found to express similar values of the genes (data not shown).

ANCHORAGE INDEPENDENT GROWTH OF PSCS To examine the ability of PSC for anchorage independent growth, we used the soft agarose

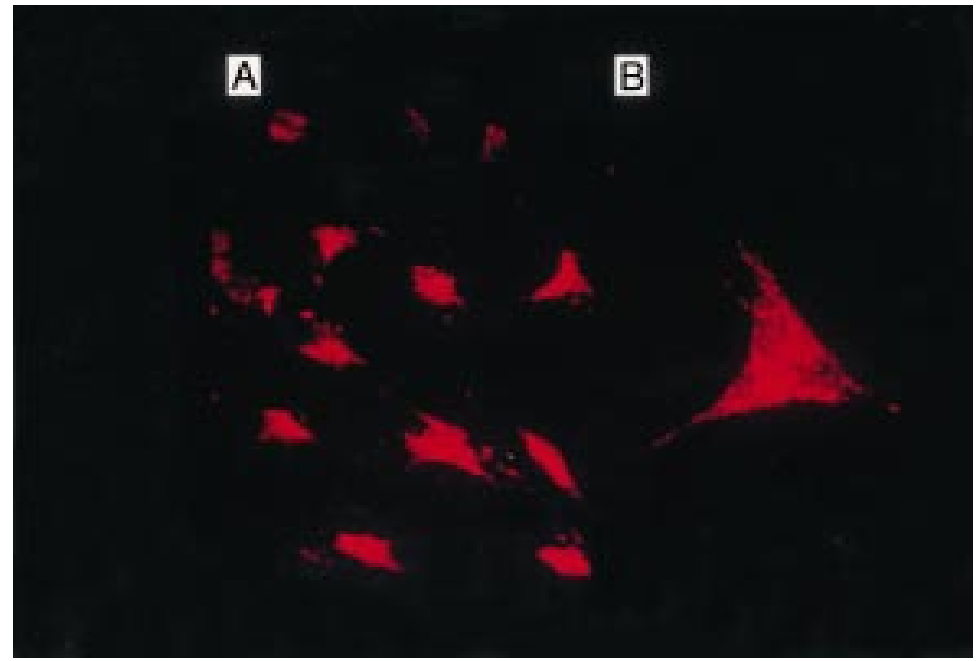

Figure 4 Type II collagen in situ reverse transcription. In situ reverse transcriptase assay was performed on the slide chamber with cultured PSCs to evaluate the expression of type II collagen $m R N A$. PCR amplification was performed with digoxigenin labelled oligonucleotide probe and sequential immunostaining with sheep anti-digoxigenin conjugated rhodamine. Cells picked up from the soft agar highly expressed type II collagen mRNA (A). High power view shows one PSC with several filopodia. Type II collagen $m R N A$ shows a scattered pattern (B) (confocal microscopy, $(A)$ original magnification $\times$ $200,(B) \times 400)$.
Table 2 Expression of protooncogenes in PSCs and SCs

\begin{tabular}{llllll}
\hline & \multicolumn{3}{l}{ PSCs } & & \multicolumn{2}{l}{ SCs } \\
\cline { 2 - 3 } \cline { 5 - 6 } & Case $1^{\star}$ & Case 2 & & Case 1 & Case 2 \\
\hline c-fos $/ \beta$ actin & $1.72 \dagger$ & 1.34 & & 0.12 & 0.93 \\
c-jun $/ \beta$ actin & 1.44 & ND & & 0.11 & 0.29 \\
c-myc $/ \beta$ actin & 2.85 & 2.17 & & 0.48 & 0.21 \\
\hline
\end{tabular}

* PSCs and SCs were obtained from two patients: case 1 and case $2 . \dagger$ The calculated ratio between band density measured by densitometry in protooncogenes and $\beta$ actin. ND $=$ not detected.

culture method. After two weeks of culture, PSCs in primary culture developed colonies in soft agar culture (fig 5A). The maximum cell number in one colony was more than 55 cells when culture continued for four weeks. To examine for differences in colony growth, PSCs and SCs of the same passage were seeded into soft agar at the same time. These experiments demonstrated a stronger tendency for colony formation by PSCs (147 colonies/104 cells at primary culture) compared with SCs (6 colonies/104 cells at primary culture). The colony number of PSCs diminished with increasing passages. The number of colonies after the eighth passage was as low as $12 / 104$ cells.

Two phenomena characterised the anchorage independent growth of PSCs. Firstly, under the phase contrast microscope, one third of the colonies has a ring formed in the extracellular matrix (fig 5B). Secondly, the morphology of the colonies changed with time, for example, culture for approximately five weeks reduced the density of colonies, so that the originally compact colony became scattered gradually.

\section{Discussion}

In this study, we isolated PSC from rheumatoid pannus lesions. Several tests were performed to identify and characterise these synoviocytes including morphological examination and detection of transcription of several protooncogenes and matrix degrading enzymes. Our results demonstrated clearly that the PSC is a fibroblast-like cell with properties common for both fibroblasts and chondrocytes. The cell did not only have specific phenotypic features, based on the observation of morphological studies, immunostaining
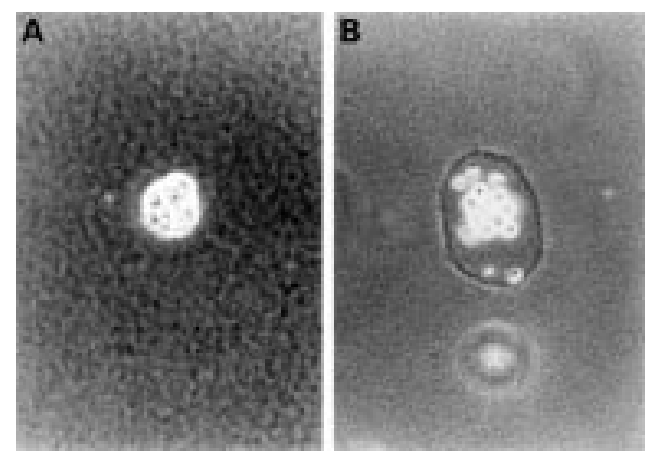

Figure 5 Colony growth in anchorage independent growth assay. After culture for four weeks, PSCs formed colonies in soft agarose (A). Under the phase contrast microscope, a number of the colonies have a ring formed in the extracellular matrix (B) (contrast microscopy, $(A)$ and (B) original magnification $\times 200$ ). 
with anti-vimentin and anti-fibroblast antibodies, safranin $\mathrm{O}$ staining, and type II collagen transcription, but it also showed some functional features, including formation of colonies in soft agar culture and high nuclear transcription. Furthermore, like activated macrophages, the PSCs expressed protease mRNAs, such as collagenase, cathepsin B, and cathepsin L. Therefore, we suggest that this fibroblast-like synoviocyte, even though forming a low percentage of the total synoviocytes, less then $5 \%$ of the cells isolated from pannus, may constitute an active component of the rheumatoid pannus lesion. In addition, the PSCs could be clearly differed from control synovial cells with positive staining of vimentin and safranin $\mathrm{O}$ as well as expression of type II collagen mRNA.

A peculiar property of fibroblast-like PSCs uncovered in this study was that of colony formation in soft agar. It has been well documented that few fibroblast populations are potentially capable of colony formation, as detected in anchorage independent growth assay. For example, in idiopathic pulmonary fibrosis, fibroblast lines derived from the fibrotic tissue form colonies at a frequency almost similar to that seen in cells derived from neonatal lung tissue. ${ }^{22}$ Early passage synoviocytes obtained from RA and streptococcal cell wall induced arthritis in rats also form colonies in soft agar. ${ }^{20}$

The nature of anchorage independent cell growth is also a marker of cell transformation. ${ }^{23}$ The fibroblasts in RA seem to be functionally 'transformed' mesenchymal cells. ${ }^{24}$ Previous studies considered the rheumatoid pannus to behave in a tumour-like fashion. ${ }^{2}$ The fact that the PSC is cable of anchorage independent growth may indicate its transformation.

The higher expression of protooncogenes in PSCs may explain partially this transformation. Higher activities of protooncogene c-fos, c-jun, and c-myc revealed abnormal nuclear transcripts in PSCs. Overexpression of protooncogene c-fos in transgenic mouse promotes mesenchymal cell proliferation in the pannus area and joint destruction without inflammatory infiltration. ${ }^{25}$ Transcription of protooncogenes also regulates matrix degrading enzymes. It is well known that c-fos binds to the jun/AP-1 protein to regulate the expression of genes, such as collagenase. ${ }^{26}$ Protooncogenes also regulate the activity of cathepsin enzymes. ${ }^{3}$ In this regard, there is ample evidence confirming the role of cathep$\sin \mathrm{B}$ and $\mathrm{L}$ in degrading cartilage collagen type II, IX, XI and cartilage proteoglycan. ${ }^{27} 28$ Using immunostaining analysis, Trabandt et $a l^{2}$ demonstrated a position distribution of cathepsin B along the synovial-cartilage junction. In this study, PSCs expressed the matrix degrading enzyme cathepsin $\mathrm{B}$ and $\mathrm{L}$ mRNA at a level similar to that of SCs. Furthermore, despite increased mRNA for c-fos and c-jun, these cells made no more collagenase than SCs. The reason that PSC does not make more protease is not clear at present.
One possible explanation is the presence of unknown factors responsible for its function in pannus.

As PSC had a number of cartilage features, we examined the expression of $S 100$, which is a marker of macrophage and dendritic cells, and it is also expressed on the cartilage cells. Our result clearly demonstrated that PSC did not express S100, which suggests that this cell population is quite distinct from macrophage or cartilage cells.

It is also possible that PSC may have abnormal differentiation induced by the process of inflammation in RA. There is a substantial evidence that fibroblasts also undergo a differentiation process either in vivo or in vitro. Scleral fibroblasts of the chick embryo differentiate into chondrocytes in soft agarose cultures. ${ }^{30}$ Such process of differentiation also occurs in well differentiated tissues, for example, during the repair of full thickness defects of articular cartilage. ${ }^{31}$ This phenomenon indicates that connective tissue fibroblasts exhibit extensive interconversion properties. $^{3233}$ In the presence of various signals in the extracellular matrix, fibroblasts can transform into osteoblasts, chondrocytes, adipocytes or even smooth muscle cells. This adaptability of fibroblasts is a key feature and represents a response to tissue damage and repair. PSC in the rheumatoid pannus lesion may also respond by transforming into other types of cells in response to the chronic inflammatory process. The tissue samples studied in this experiment were obtained from joints at a comparatively late stage in the disease process, it is also quite possible that the granulation tissue present adjacent to cartilage and bone in these joints is largely related to the formation of osteophytes, and the cells are able to sythesise components of articular cartilage. The expression of protooncogenes may contribute, at least in part, by promoting cellular interconversion. In this regard, PSC may be the source of the cells responsible for the initiation of pannus.

The underlying mechanisms for the difference in ability of PSC and SCs to form colonies were not investigated in this study. We have already cloned three types of synoviocytes from RA synovial tissues, including dendritic cells, macrophage cells and fibroblast-like cells. ${ }^{14}$ Although cultured PSCs had more filopodia compared with fibroblasts, they stained negatively with anti-dendritic cell antibodies. The PSC demonstrated an intermediate type between type A and type B synoviocytes. This finding was also supported by morphological findings, the cells in the rheumatoid pannus tissue were mesenchymal in appearance. ${ }^{13}$ Moreover, PSCs had several phenotypic and functional characteristics that were not present in SCs as mentioned above. Therefore, it is reasonable to consider PSC as an alternative synoviocyte compared with SCs.

Further research investigating the proliferation and differentiation of PSC would perhaps permit the blockage of the process leading to perpetuation of joint destruction in RA. 
We thank Drs Steffen Gay and S A Allard for their useful discussion and critical reading of the manuscript. This work was supported by grants from the Ministry of Education, Science
and Culture of Japan, the Ministry of Health and Welfare of Japan, and a grant from Kanagawa Foundation for Medical Science.

1 Nishioka K. Tumorigenic property of rheumatoid synovial cell. (In Japanese) Rheumatology 1994;12:14-9.

2 Hamilton JA. Hypothesis: In vitro evidence for the invasive and tumor-like properties of the rheumatoid pannus. J Rheumatol 1983;10:845-51.

3 Gay S, Gay RE, Koopman WJ. Molecular and cellular mechanisms of joint destruction in rheumatoid arthritis: two cellular mechanisms explain joint destruction? Ann Rheum Dis 1993;(suppl) 52:S39-47.

4 Nishioka K, Nakajima T, Aono H, Hasunuma T, Yamamoto K. Establishment of rheumatoid synovial cell clones of monoclonal origin Arthritis Rheum 1994;(suppl 9) 37:S310.

5 Zvaifler NJ, Firestein GS. Pannus and pannocytes. Alternative models of joint destruction in rheumatoid arthritis. Arthritis Rheum 1994;37:783-9.

6 Kobayashi I, Ziff M. Electron microscopic studies of the cartilage-pannus junction in rheumatoid arthritis. Arthritis cartilage-pannus junction

7 Shiozawa S, Shiozawa K, Fujita T. Morphologic observation in the early phase of the cartilage-pannus junction. Arthritis Rheum 1983;26:472-8.

8 Muirden KD. Microscopic studies of the synovial-cartilage junction in rheumatoid arthritis. Eur J Rheumato Inflamm 1982;5:30-8.

9 Cooke TDV. Rheumatoid arthritis pannus: true or false? (letter) Arthritis Rheum 1985;28:1195-7

10 Allard SA, Muirden KD, Camplejohn KL, Maini RN Chondrocyte-derived cells and matrix at the rheumatoid cartilage-pannus junction identified with monoclonal antibodies. Rheumatol Int 1987;7:153-9.

11 Klareskog L, Johnell O, Hulth A, Holmdahl R, Rubin K. Reactivity of monoclonal anti-type II collagen antibodies with cartilage and synovial tissue in rheumatoid arthritis and osteoarthritis. Arthritis Rheum 1986;29:730-8.

12 Fassbender HG. Histomorphologic basis of articular cartilage destruction in rheumatoid arthritis. Coll Relat cartilage destructio

13 Shiozawa S, Tokuhisa T. Contribution of synovial mesenchymal cells to the pathogenesis of joint destruction in rheumatoid arthritis. Seminars in Arthritis and Rheumatism 1992;21:267-73.

14 Goto M, Sasano M, Yamanaka H, Miyasaka N, Kamatani $\mathrm{N}$, Inoue $\mathrm{K}$, et al. Spontaneous production of an interleukin 1-like factor by cloned rheumatoid synovia cells in long-term culture. J Clin Invest 1987;80:786-96.

15 Hasunuma T, Nakajima T, Aono H, Sato K, Matsubara T, Yamamoto K, et al. Establishment and characterization of synovial cell clones with integrated human T-cell leukemia
virus type-I. Clin Immunol Immunopathol 1994;72:90-7.

16 Ishikawa $\mathrm{K}$. Chondrocytes that accumulate proteoglycans and inorganic pyrophosphate in the pathogenesis of chondrocalcinosis. Arthritis Rheum 1985;28:118-9.

17 Muller-Ladner U, Kriegsmann J, Tschopp J, Gay RE, Gay $\mathrm{S}$. Demonstration of granzyme A and perforin messenger
RNA in the synovium of patients with rheumatoid arthritis. Arthritis Rheum 1995;38:477-84.

18 Chomczynski P, Sacch N. Single-step method of RNA isolation by acid guanidinium thiocyanate-phenol-chloroform extraction. Anal Biochem 1987;162:156-9.

19 Kinoshita T, Shimoyama $M$, Tobinai $K$, Ito $M$, Ito $S$, Ikeda $\mathrm{S}$, et al. Detection of mRNA for the tax $1 / \operatorname{rex} 1$ gene of human T-cell leukemia virus type-I in fresh peripheral blood mononuclear cells of adult T-cell leukemia patients and viral carriers by using the polymerase
Proc Natl Acad Sci USA 1989;86:5620-4.

20 Lafyatis R, Remmers EF, Roberts AB, Yocum DE, Sporn MB, Wilder RL. Anchorage-independent growth of synoviocytes from arthritic and normal joints. Stimulation by exogenous platelet-derived growth factor and inhibition by transforming growth factor-beta and retinoids. J Clin by transforming growth

21 Steinert PM, Roop DR. Molecular and cellular biology of intermediate filaments. Ann Rev Biochem 1988;57:593625

22 Torry DJ, Richards CD, Podor TJ, Gauldie J. Anchorageindependent colony growth of pulmonary fibroblasts derived from fibrotic human lung tissue. J Clin Invest 1994;93:1525-32.

23 Freedman VH, Shin S. Cellular tumorigenicity in nude mice: correlation with cell growth in semi-solid medium. mice: correlation with

24 Fassbender HG, Simmling-Annefeld M, Stofft E. Transformation der synovialzellen bie rheumatoiden arthritis. Verhandlungen der Deutschen Gesellschaft fur Pathologie 1980;64:193-212

25 Shiozawa S, Tanaka Y, Fujita T, Tokuhisa T. Destructive arthritis without lymphocyte infiltration in $\mathrm{H} 2$-c-fos transgenic mice. J Immunol 1992;148:3100-4

26 Schonthal A, Herrlich P, Rahmsdort HJ, Ponta H. Requirement for fos gene expression in the transcriptional activation of collagenase by other oncogenes and phorbol esters. Cell 1988;54:325-34.

27 Nguyen Q, Mort JS, Roughley PJ. Cartilage proteoglycan agregate is degraded more extensively by cathepsin $\mathrm{L}$ aggregate is degraded more extensively by cathe
than by cathepsin B. Biochem J 1990;266:569-73.

28 Maciewicz RA, Wotton SF, Etherington DJ, Duance VC. Susceptibility of the cartilage collagens type II, IX and XI to degradation by the cysteine proteinases, cathepsin B and L. FEBS Lett 1990;269:189-93.

29 Trabandt A, Gay RE, Fassbender HG, Gay S. Cathepsin B in synovial cells at the site of joint destruction in rheumatoid arthritis. Arthritis Rheum 1991;34:1444-51.

30 Watanabe K, Yagi K, Ohya Y, Kimata K. Scleral fibroblasts of the chick embryo differentiate into chondrocytes in
soft-agar culture. In Vitro Cell Dev Biol 1992;28A:603-8.

31 Shapiro F, Koide S, Glimcher MJ. Cell origin and differentiation in the repair of full-thickness defects of articular cartilage. J Bone Joint Surg 1993;75A:532-53.

32 Conrad GW, Hart GW, Chen Y. Differences in vitro between fibroblast-like cells from cornea, heart and skin of embryonic chicks. J Cell Sci 1977;26:119-37.

33 Reddi AH, Gay RE, Gay S, Miller EJ. Transitions in collagen types during matrix-induced cartilage, bone and bone marrow formation. Proc Natl Acad Sci USA 1977; 74:5589-92. 